\title{
Characterization of the Colletotrichum Species Causing Anthracnose in Andean Blackberry in Colombia
}

Lucía Afanador-Kafuri, Faculty of Agricultural Sciences, Universidad Nacional de Colombia-Medellín, A. A. 1779, Medellín, Colombia; Alonso González, Tropical Fruit Project, International Center for Tropical Agriculture (CIAT), A. A. 6713, Cali, Colombia; Lederson Gañán, CIAT and Faculty of Agricultural Sciences, Universidad de Caldas, A. A. 275, Manizales, Colombia; Juan Fernando Mejía, Plant Pathology, CIAT; Nadya Cardona, Universidad de Antioquia, A. A. 1226, Medellín, Colombia; and Elizabeth Alvarez, Plant Pathology, CIAT

\begin{abstract}
Afanador-Kafuri, L., González, A., Gañán, L., Mejía, J. F., Cardona, N., and Alvarez, E. 2014. Characterization of the Colletotrichum species causing anthracnose in Andean blackberry in Colombia. Plant Dis. 98:1503-1513.

Since 1992, anthracnose of Andean blackberry (Rubus glaucus) has generated losses as high as $40 \%$ for farmers in Colombia. In this study, our goal was to characterize 240 Colletotrichum isolates from Andean blackberry in eight areas of Colombia. These isolates were evaluated according to morphological characteristics, sensitivity to benomyl, pathogenicity, and genetic variability. Identification of the genus Colletotrichum was achieved by using species complex-specific polymerase chain reaction primers. A multilocus phylogeny approach was used to identify isolates to the species level with sequences from the ribosomal internal transcribed spacer region and partial sequences of the actin, $\beta$ tubulin 2, calmodulin, chitin synthase 1 , glutamine synthetase, and

glyceraldehyde-3-phosphate dehydrogenase genes. Most of the isolates were identified as Colletotrichum gloeosporioides sensu lato, were associated with the Castilla ecotype, showed high sensitivity to benomyl, and were highly aggressive. Isolates identified as C. acutatum sensu lato were found mainly on the Thornless ecotype, were highly resistant to benomyl, and showed intermediate aggressiveness. Only three isolates were identified as $C$. boninense sensu lato. The species identified included C. fructicola, C. kahawae subsp. ciggaro, C. godetiae, C. karstii, C. brassicicola, and undetermined Colletotrichum spp. This study is the first report of these species associated with anthracnose in Andean blackberry.
\end{abstract}

Andean blackberry (Rubus glaucus Benth.), also known as mora de Castilla in Spanish, is a tropical fruit native to the northern Andes of South America and is now a crop of economic importance in Latin American countries such as Colombia, Costa Rica, Ecuador, Guatemala, Honduras, Mexico, and Panama (19,23). In Colombia, the Andean blackberry is cultivated mainly by small- and mediumscale farmers, and is a major source of income for more than 12,000 rural families in midaltitude regions $(1,500$ to $2,500 \mathrm{~m}$ above sea level) $(23,27)$. However, the production potential of this crop is constrained by poor agronomic practices, such as lack of fertilizer application and high plant densities (4), dependence on a few varieties that are of poor genetic quality for planting materials (4), and susceptibility of the current planted varieties to diseases, particularly anthracnose (Colletotrichum spp.), fruit rot or gray mold (Botrytis cinerea), and downy mildew (Peronospora sp.) $(6,42,43)$

Since 1992, when records first became available, anthracnose of Andean blackberry has generated losses as high as $40 \%$ for farmers in Colombia $(16,42,43)$. The disease is prevalent in areas with temperatures ranging from 13 to $22^{\circ} \mathrm{C}$ and relative humidity above $92 \%$. The fungus attacks fruit, inducing rot and mummification. It also attacks stems and branches, causing symptoms such as black lesions and dieback (Fig. 1). Disease incidence and severity depend on locality and weather conditions and, therefore, vary over sites from year to year.

Previous morphological, molecular, and phylogenetic studies of Colletotrichum populations attacking Andean blackberry suggest that Colletotrichum gloeosporioides and C. acutatum are causal agents of anthracnose in this crop $(5,35,36)$. Recently, however, $C$.

Corresponding author: E. Alvarez, E-mail: e.alvarez@cgiar.org

Accepted for publication 21 April 2014.

http://dx.doi.org/10.1094/PDIS-07-13-0752-RE

(C) 2014 The American Phytopathological Society gloeosporioides and C. acutatum were determined to be species complexes, each with several species that share morphological and even genetic similarities $(14,47)$. Multilocus phylogenetic studies are used to delimit Colletotrichum spp. within these two $(2,14,15,29,30,33,47)$ and other Colletotrichum complexes, such as the $C$. boninense species complex, which encompasses about 17 species and affects a wide range of hosts (15), and the $C$. graminicola species complex, which is associated with anthracnose in grass species $(9,12,13)$.

For example, Prihastuti et al. (33) elucidated the genetic relationship existing between the species $C$. asianum, $C$. siamense, and $C$. fructicola within the $C$. gloeosporioides complex on the basis of analyzing data on sequences from the ribosomal internal transcribed spacer (ITS) region and the following genes: actin (ACT; partial), $\beta$-tubulin 2 (TUB 2), calmodulin (CAL), glutamine synthetase (GS), and glyceraldehyde-3-phosphate dehydrogenase (GAPDH). Cai et al. (8) recommend a polyphasic strategy for recognizing and identifying species within the Colletotrichum genus. This strategy must include morphological, physiological, biochemical, and pathogenicity studies, together with phylogenetic analysis of multiple genes, using sequencing data from type specimens.

Given the importance of anthracnose in Colombia's main blackberry-producing areas, additional studies are needed to better understand the disease and its causal agents. Such information is required for planning appropriate pest management and control. Crucial to understanding this disease's epidemiology is not only the correct and timely identification of the pathogens responsible for anthracnose in Andean blackberry but also the determination of the pathogen populations' variability. Such understanding would contribute toward developing genetic improvement programs for this crop.

To meet these needs, our study aimed to identify the Colletotrichum spp. affecting Andean blackberry in Colombia, and to characterize a large set of Colletotrichum isolates according to specific morphological and cultural characteristics, pathogenicity, and genetic diversity. 


\section{Materials and Methods}

Sampling, isolation, and conservation of the fungus. From 2004 to 2008, samples of symptomatic plant tissues from Andean blackberry were collected at several sites from 38 municipalities of eight departments in Colombia (i.e., Antioquia, Caldas, Cundinamarca, Huila, Quindío, Risaralda, Santander, and Valle del Cauca; Fig. 2). At each site, samples were categorized and collected according to symptom type (necrosis around the spines, stem necrosis, dieback in branches, necrosis in fruit or floral buds, and mummification of fruit; Fig. 1) and phenotypic diversity of the crop (blackberry ecotype).

To isolate the fungus, $0.5-\mathrm{cm}$ fragments were cut from both healthy and diseased tissues. The tissues were then disinfected (first in $70 \%$ ethanol for $1 \mathrm{~min}$ and then in 1\% sodium hypochlorite for $2 \mathrm{~min}$ ), washed in sterilized distilled water for $1 \mathrm{~min}$, and dried on sterilized paper towels. Five fragments of disinfected blackberry tissue were then placed on potato dextrose agar (PDA; Difco Laboratories) medium amended with $1 \mathrm{ml}$ of $25 \%$ lactic acid per liter (Merck \& Co., Inc.) and incubated at room temperature $\left(24^{\circ} \mathrm{C}\right)$ under continuous light.

The cultures were evaluated at 2-day intervals until fungal colonies began to develop. Portions of mycelium obtained from colony edges were then transferred to fresh, acidified PDA (APDA) medium for purification and to obtain mono-conidial isolates.

Pieces of sterilized filter paper, colonized with mycelium and conidia from monoconidial isolates of the fungus, were stored at $4^{\circ} \mathrm{C}$. For this study, 240 isolates were selected according to their geographical origin, blackberry ecotype ('Castilla' or 'Thornless'), diseased tissue, and colony morphology of each fungal strain on APDA medium (Table 1).

Morphological characterization. All the Colletotrichum isolates were examined for their cultural and morphological traits. Mycelial plugs ( $0.5 \mathrm{~mm}$ in diameter) were taken from the edges of 12-day-old colonies, transferred to the middle of 9-cm-diameter petri dishes containing APDA medium, and incubated at $22 \pm 1{ }^{\circ} \mathrm{C}$ and a light-and-dark cycle at 12 and $12 \mathrm{~h}$, respectively, using a cool, white, fluorescent light. Colony characteristics (i.e., texture, density, mycelial color on the upper and lower surfaces, presence or absence of sectors, type of conidiation, and fungal mat edges) were determined visually after 15 days of incubation. Colony color was rated according to Munsell Color Charts (25). Growth rate was calculated as the 12-day average of mean daily growth (millimeters per day).

Conidia were harvested from 15-day-old cultures incubated under the same conditions mentioned above. In most cases, sporulation was induced by cutting portions of the colony with a scalpel, thus mechanically injuring the mycelium.
Appressorium formation was induced by germinating spores in drops of deionized water in the wells of single, concave, microscope slides (Parco Scientific Co.) and incubating them in a humid chamber overnight (11). Each well contained $30 \mu$ of conidial suspension.

The size and shape of conidia and appressoria were observed under an Olympus CX41 light microscope (Olympus Deutschland $\mathrm{GmbH}$ ), photographed with an Olympus digital camera (Olympus C5060ADU), and then measured with the software program Scion Image for Windows (Scion Corporation). For each isolate, 60 conidia and 21 appressoria from each replicate were analyzed.

Additionally, the presence or absence of the sexual phase was evaluated based on micropreparations of fungal structures that consisted of round, compact, hard, dark-brown- or black-colored masses which were immersed in the medium. These masses were indicative of sexually derived perithecia or primordia.

Morphological studies were conducted with three replicates, using a randomized complete block design. To establish differences

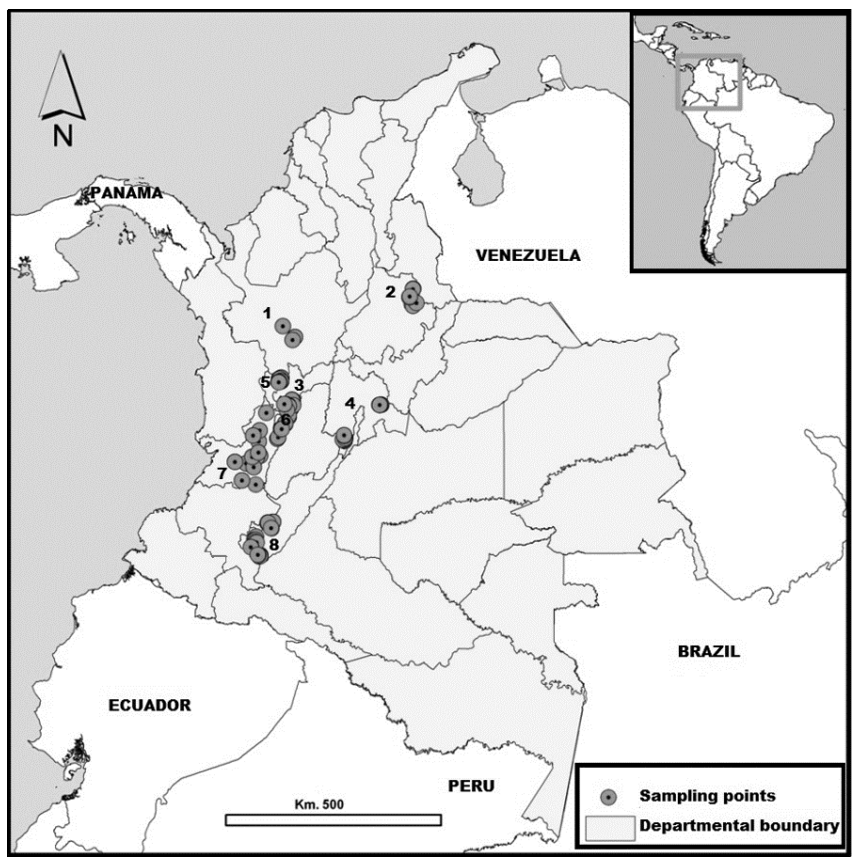

Fig. 2. Andean blackberry-producing areas in Colombia where Colletotrichum isolates were collected. Georeference points of each collection site (38 in all) are marked with a circle. Numbers refer to Colombian departments: 1, Antioquia; 2 , Santander; 3, Caldas; 4, Cundinamarca; 5, Risaralda; 6, Quindío; 7, Valle del Cauca; 8, Huila.
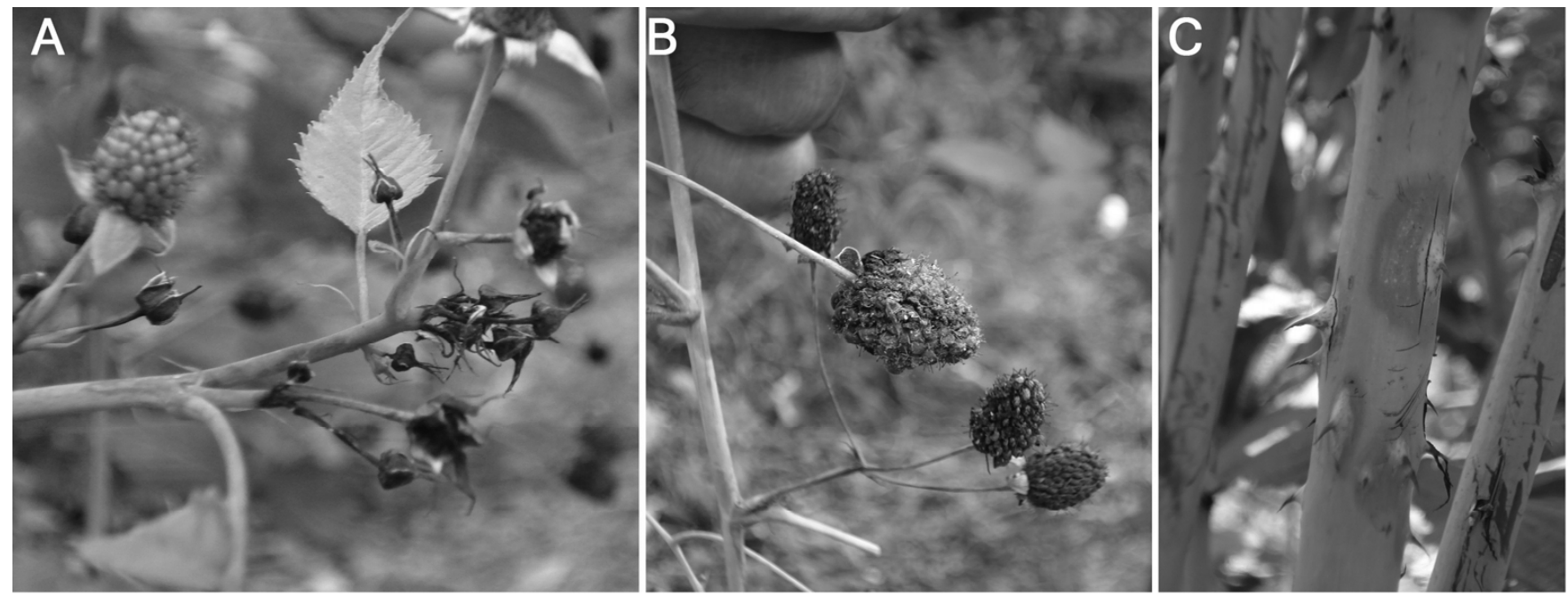

Fig. 1. Anthracnose symptoms in Andean blackberry. A, Dieback and floral bud rot. B, Fruit rot and mummification. C, Stem lesions. 
between isolates, morphological data were subjected to multiple correspondence and principal components analyses, and growth rate values to analysis of variance (ANOVA). Separation of means was conducted using the Ryan-Einot-Gabriel-Welsch (REGW) multiple step-down range test $(\alpha \leq 0.05)$ (37).

Evaluating sensitivity to benomyl. Each isolate was placed on PDA plates supplemented with benomyl (Benlate $50 \mathrm{WP}$; Dupont) at $5 \mu \mathrm{g}$ a.i. $\mathrm{ml}^{-1}$. Sensitivity or resistance of isolates to benomyl was evaluated by measuring colony radius, which was then used to calculate colony area. Resulting data were expressed as percentages of inhibition (\% I) of fungal growth in relation to the fungal growth on unamended PDA medium (control). A randomized complete block design was used, with three replicates. Data of the \% I of growth were arcsine-square root transformed and then analyzed using an ANOVA to establish differences between isolates, and separation of means was carried out with a REGW test $(\alpha \leq 0.05)$ (37). Isolates were termed highly sensitive if percentage of growth inhibition was greater than $90 \%$, sensitive at $>75$ to $90 \%$ inhibition, moderately resistant at $>60$ to $75 \%$, resistant at $>40$ to $60 \%$, and highly resistant if growth inhibition was lower than $40 \%$.

Pathogenicity tests. The aggressiveness of 240 Colletotrichum isolates was evaluated by artificially inoculating three replicates of Castilla blackberry stems (20-cm-long cuttings, averaging $1 \mathrm{~cm}$ in diameter) per isolate, following the method of Stewart et al. (40). The stems had previously been disinfected with a solution of $1.5 \%$ sodium hypochlorite, washed with sterilized distilled water, and dried at room temperature. Each stem was inoculated with a 0.5$\mathrm{cm}$ disc of APDA medium carrying fungal mycelium and then sealed with a Parafilm M strip (Bemis Flexible Packaging Com- pany). Three stems inoculated with fungus-free APDA discs were used as controls for each treatment (isolate tested).

Inoculated stems were then placed in transparent covered plastic trays, the bottoms of which contained water (1 cm deep) to maintain humidity, and incubated at $22^{\circ} \mathrm{C}$, with $8 \mathrm{~h}$ of daylight.

The width and length of each resulting lesion were measured from day 5 to day 20 after inoculation. Lesion area was estimated by assuming an elliptical shape.

Lesion area data, recorded on alternate days, were used to estimate the area under the disease progress curve (AUDPC). For statistical analysis, AUDPC data were log transformed, then analyzed, assuming a randomized complete block experimental design and using SAS (version 9.2; SAS Institute Inc.) (37). ANOVA was performed to establish differences between isolates and the REGW test was run to evaluate statistically significant differences at $\alpha \leq$ 0.05 (37).

Molecular characterization. DNA isolation and purification. Each isolate was cultured for 10 days in an Erlenmeyer flask containing $100 \mathrm{ml}$ of liquid potato dextrose medium (potato at 200 $\mathrm{g} / \mathrm{liter}$, dextrose at $20 \mathrm{~g} / \mathrm{liter}$, and 1 liter of distilled water) plus $60 \mu \mathrm{l}$ of ampicillin (20 mg/liter). Cultures were incubated at room temperature $\left( \pm 24^{\circ} \mathrm{C}\right)$ under constant artificial light and no agitation.

DNA extraction and purification were performed according to Mahuku (22), as modified by Alvarez et al. (3). The DNA pellet was dissolved in $100 \mu \mathrm{l}$ of Tri-EDTA buffer $(10 \mathrm{mM}$ Tri-HCL and $1 \mathrm{mM}$ EDTA, $\mathrm{pH}$ 8.0). Quality was determined by electrophoresis in $0.8 \%$ agarose gel and quantified by fluorometry, using a DyNA Quant 200 Fluorometer (Hoefer, Inc.). The DNA was subsequently diluted to $5 \mathrm{ng}^{-1} \mathrm{l}^{-1}$, as a working solution for polymerase chain reaction $(\mathrm{PCR})$ tests.

Table 1. Morphological, cultural, and pathogenic characteristics of the 240 Colletotrichum isolates obtained from Andean blackberry and grouped according to species complex and genetic diversity cluster, as identified through intersimple sequence repeat (ISSR) analysis ${ }^{\mathrm{u}}$

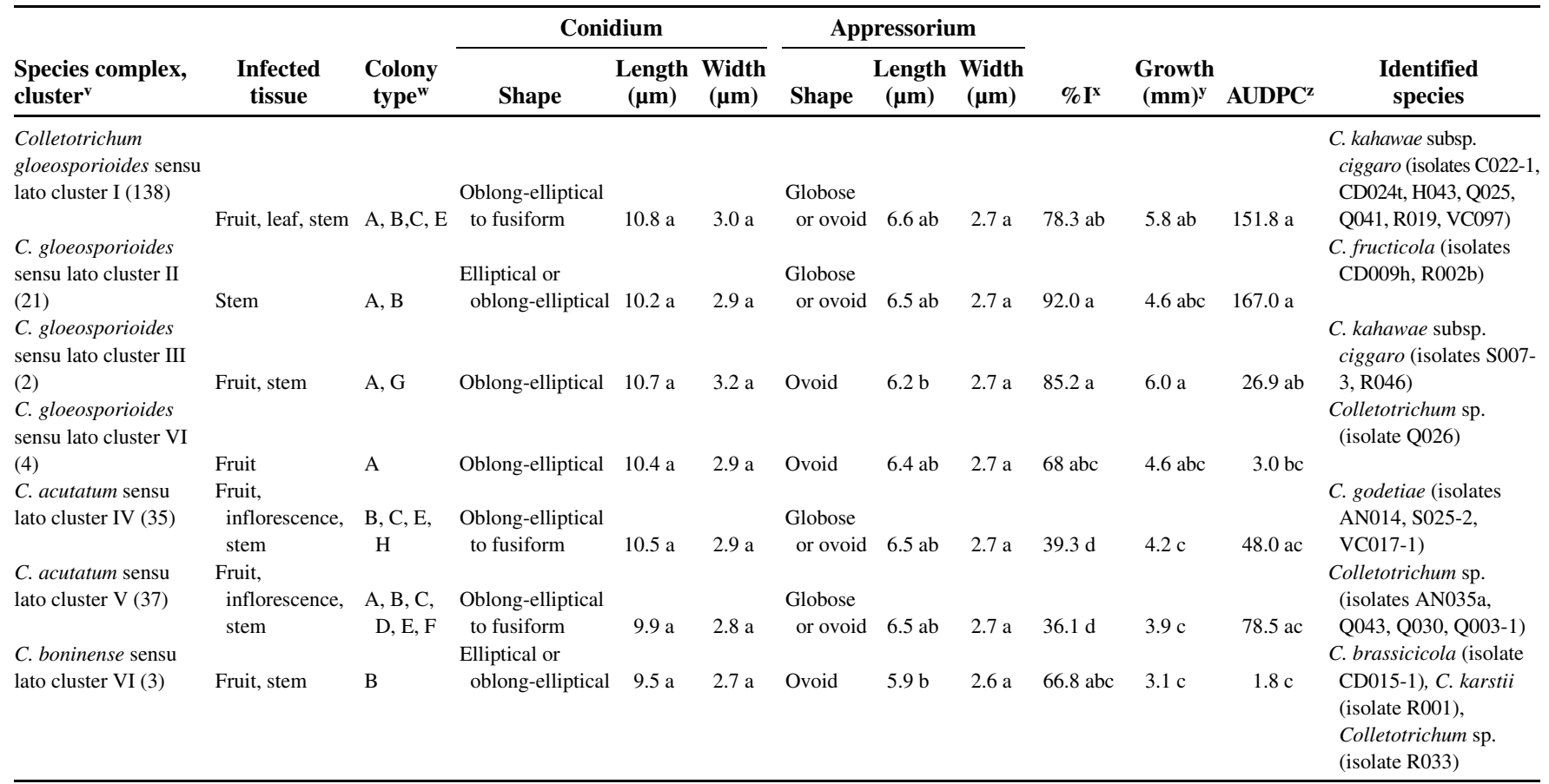

\footnotetext{
"Mean difference between each group is significant at the 0.05 level; values with same letters based on REGW multiple range test in a column do not differ significantly.

${ }^{\mathrm{v}}$ ISSR and M13 clusters. Values in parentheses show the number of isolates in each group.

${ }^{\mathrm{w}} \mathrm{A}=$ gray colony, cottony texture, high density, sectors absent, irregular edges; $\mathrm{B}=$ gray to olive-gray colony, cottony texture, high density, sectors absent, uniform edges; $\mathrm{C}$ = pinkish- to grayish-white colony, fructification present in colony center, cottony texture, sectors absent, high density, uniform edges; D = gray colony, fructification present in colony center, velvety texture, high density, sectors absent, uniform edges; $\mathrm{E}=$ gray colony, fructification present in colony center, cottony texture, high density, sectors absent, uniform edges; $\mathrm{F}=$ gray colony, abundant fructification rings throughout colony, velvety texture, intermediate density, sectors absent, uniform edges; $\mathrm{G}=$ pinkish-white colony, reddish-yellow fructification rings throughout colony, velvety texture, intermediate density, sectors present, uniform edges; $\mathrm{H}=$ olive-gray colony, cottony texture, high density, sectors absent, uniform edges.

${ }^{x}$ Sensitivity to benomyl is indicated as percentage of inhibition (\% I) of colony growth in relation to the control.

y Growth rate on potato dextrose agar $\left(\mathrm{mm} \mathrm{day}^{-1}\right)$.

$\mathrm{z}$ AUDPC $=$ area under disease progress curve.
} 
Identification of Colletotrichum complexes using PCR. The amplification of complex-specific regions of the ITS region was performed using the universal primer ITS4, together with the primers specific for $C$. acutatum sensu lato (CaInt2), C. gloeosporioides sensu lato (CgInt), and $C$. boninense sensu lato (Coll) $(1,24,31,38)$. The amplification of the regions associated with the TUB 2 gene was performed with the TBCA primer (specific for $C$. acutatum sensu lato) and the primer TBCG (specific for C. gloeosporioides sensu lato), in combination with the conserved primer TB5, which is useful for both complexes $(1,41)$.

The DNAs of strains GND-1, C339, Tom 10, Tom 21, Pass 063, and Pass 52 were used as positive controls for amplification. The negative control was high-performance liquid chromatography (HPLC)-grade ultrapure water.

Each reaction comprised $1 \times$ enzyme buffer, $0.2 \mathrm{mM}$ each dNTP, $0.5 \mu \mathrm{M}$ each primer, $1.5 \mathrm{mM} \mathrm{MgCl}_{2}$, DNA at $0.2 \mathrm{ng} \mu \mathrm{l}^{-1}$, HPLCgrade ultrapure water to complete a final volume of $25 \mu \mathrm{l}$, and Biolase Taq DNA polymerase (Bioline Inc.) at $0.1 \mathrm{U}^{-1}$. DNA amplification was performed using a PTC-100 thermal cycler (MJ Research), with an initial denaturing step of $95^{\circ} \mathrm{C}$ for $5 \mathrm{~min} ; 40$ cycles at $95^{\circ} \mathrm{C}$ for $30 \mathrm{~s}$ and $30 \mathrm{~s}$ at $61^{\circ} \mathrm{C}$ for $\mathrm{Coll}, 62^{\circ} \mathrm{C}$ for $\mathrm{CgInt}$, and $60^{\circ} \mathrm{C}$ for $\mathrm{CaInt} 2$; plus extension for $90 \mathrm{~s}$ at $72^{\circ} \mathrm{C}$. A final extension for $4 \mathrm{~min}$ at $72^{\circ} \mathrm{C}$ was used post-cycling. Conditions for the TBCA and TBCG primers were published by Talhinhas et al. (41).

Amplification products $(6 \mu \mathrm{l})$ were separated by electrophoresis in a $1.5 \%$ agarose gel in $0.5 \times$ Tris-borate EDTA buffer, stained with $1.3 \mu \mathrm{M}$ ethidium bromide at $5 \mathrm{~V} \mathrm{~cm}^{-1}$ for $4 \mathrm{~h}$, and visualized using UV light. Each gel had two lanes loaded with $2 \mu \mathrm{l}$ of the molecular weight marker Hyperladder II to facilitate comparisons of sample band sizes. Images were captured using the gel reader software Gel Doc 2000 (Bio-Rad Laboratories, Inc.).

Determining genetic diversity with intersimple sequence repeat and M13 PCR markers. The 240 Colletotrichum isolates were tested using five different primers of the type intersimple sequence repeat (ISSR)- $(\mathrm{CAG})_{5},(\mathrm{AGG})_{5},(\mathrm{GACA})_{4},(\mathrm{GACAC})_{3}$, and (TCC) $)_{5}$ - and the MR primer (5' GAGGGTGGCGGTTCT 3', core sequence of phage M13), which were previously reported to produce polymorphic and reproducible DNA fingerprint patterns from C. acutatum sensu lato and C. gloeosporioides sensu lato (41). Each PCR reaction $(25 \mu \mathrm{l})$ consisted of $1 \times$ enzyme buffer, $0.2 \mathrm{mM}$ each dNTP, $0.5 \mu \mathrm{M}$ primer, $1.5 \mathrm{mM} \mathrm{MgCl}_{2}$, DNA at $0.2 \mathrm{ng} \mathrm{l}^{-1}$,
HPLC-grade ultrapure water to a final volume of $25 \mu \mathrm{l}$, and Biolase Taq DNA polymerase (Bioline Inc.) at $0.1 \mathrm{U} \mathrm{\mu l}^{-1}$. The PCR conditions for ISSR and M13 amplifications consisted of an initial denaturation carried out with a preliminary cycle of $5 \mathrm{~min}$ at $95^{\circ} \mathrm{C}$; followed by 30 cycles of denaturation for $30 \mathrm{~s}$ at $95^{\circ} \mathrm{C}$; annealing for $30 \mathrm{~s}$ at $60^{\circ} \mathrm{C}$ for primers $(\mathrm{CAG})_{5},(\mathrm{AGG})_{5}, \mathrm{MR}$, and $(\mathrm{TCC})_{5}$ or $48^{\circ} \mathrm{C}$ for primers $(\mathrm{GACA})_{4}$ and $(\mathrm{GACAC})_{3}$; and extension for 1.5 min at $72^{\circ} \mathrm{C}$. The amplification products were separated and visualized, as mentioned above.

Genetic diversity was interpreted according to general band patterns, assigning a value of one (1) if present and zero (0) if absent and generating a binary data matrix. Genetic relationships among isolates were ascertained using multiple correspondence analyses (MCA) and constructing a three-dimensional scatter plot. The rowcoordinates profile was obtained from the MCA, while group assignment was obtained from cluster analysis and average nearest neighbor distance calculations. All data were analyzed with SAS, version 9.2 for Windows (37).

Multilocus sequencing and phylogenetic analysis. Specimen selection. A subset of 22 isolates was selected to represent the Colletotrichum complexes identified and the range of genetic diversity found according to the M13 and ISSR-PCR marker analyses.

PCR amplification and sequencing. Nucleotide sequences were determined for seven PCR-amplified nuclear amplicons, including the complete ribosomal ITS region, ACT, TUB2, GAPDH, chitin synthase 1 (CHS-1), CAL, and GS genes, which were amplified and sequenced using the primer pairs ITS-5 + ITS-4 (48), ACT512F + ACT-783R (10), Bt2a + Bt2b (17), GDF1 + GDR1 (46), CHS-79F + CHS-354R (10), CL1 + CL2A (26), and GSF1 + GSR1 (39), respectively.

The PCR amplifications were performed in a $25-\mu 1$ reaction volume, consisting of $10 \mathrm{ng}$ of DNA template, a $1 \times$ final concentration of Fermentas DreamTaq Green PCR Master Mix (Applied Biosystems Inc.), and $0.5 \mu \mathrm{M}$ each primer. The reactions were performed with a thermal cycler (PTC-100; MJ Research Inc.), using the thermal programs as previously described for ITS, ACT, TUB 2, GAPDH, and GS (33), and for CHS-1 and CAL (47).

The PCR products were purified with the PEG- $\mathrm{NaCl}$ method. Briefly, the sample was mixed with $1 \times$ volume of $20 \%$ PEG-NaCl [PEG, MW 6,000, and $2.5 \mathrm{M} \mathrm{NaCl}$ ) and incubated for $15 \mathrm{~min}$ at

Table 2. GenBank accession numbers of Colletotrichum isolates from Andean blackberry in Colombia as identified by multilocus phylogenetic analysis

\begin{tabular}{|c|c|c|c|c|c|c|c|c|}
\hline \multirow[b]{2}{*}{ Colletotrichum spp. } & \multirow[b]{2}{*}{ Isolate code } & \multicolumn{7}{|c|}{ GenBank accession numbers ${ }^{\mathrm{z}}$} \\
\hline & & ACT & CAL & CHS-1 & GAPDH & GS & ITS & TUB 2 \\
\hline Colletotrichum brassicicola & CD015-1 & KC859967 & & KC859992 & KC860010 & $\ldots$ & JN715844 & KC860036 \\
\hline \multirow[t]{2}{*}{ C. fructicola } & CD009h & KC859959 & KC859977 & KC859984 & KC860002 & $\ldots$ & JN715843 & KC860028 \\
\hline & $\mathrm{R} 002 \mathrm{~b}$ & KC859960 & KC859978 & KC859985 & KC860003 & $\ldots$ & KC860041 & KC860029 \\
\hline \multirow[t]{3}{*}{ C. godetiae } & AN014 & KC859961 & $\ldots$ & KC859986 & KC860004 & $\ldots$ & JN715834 & KC860030 \\
\hline & S025-2 & KC859962 & $\ldots$ & КС859987 & КC860005 & $\ldots$ & КС860043 & KC860031 \\
\hline & VC017-1 & KJ001105 & & KJ001112 & KJ001116 & & KJ001123 & KJ001127 \\
\hline \multirow[t]{9}{*}{ C. kahawae subsp. ciggaro } & $\mathrm{C} 022-1$ & KJ001102 & KJ001106 & KJ001109 & KJ001113 & KJ001117 & KJ001120 & KJ001124 \\
\hline & $\mathrm{CD} 024 \mathrm{t}$ & KC859955 & KC859973 & КС859981 & КС859998 & КС860019 & JN715845 & КС 860024 \\
\hline & H043 & КC859953 & КC859971 & КC859979 & КС859996 & КC860015 & JN715838 & KC860022 \\
\hline & Q025 & KJ001103 & KJ001107 & KJ001110 & KJ001114 & KJ001118 & KJ001121 & KJ001125 \\
\hline & Q041 & KJ001104 & KJ001108 & KJ001111 & KJ001115 & KJ001119 & KJ001122 & KJ001126 \\
\hline & R019 & KC859954 & KC859972 & KC859980 & KC859997 & KC860017 & JN715847 & KC860023 \\
\hline & R046 & КC859957 & КС859975 & KC859982 & КC860000 & КС860018 & JN715848 & KC860026 \\
\hline & S007-3 & KC859958 & KC859976 & KC859983 & KC860001 & KC860014 & JN715836 & KC860027 \\
\hline & VC097 & КC859956 & KC859974 & KF312208 & КC859999 & КС860021 & JN715837 & KC860025 \\
\hline \multirow{7}{*}{$\begin{array}{l}\text { C. karstii } \\
\text { Colletotrichum sp. }\end{array}$} & R001 & KC859968 & $\ldots$ & KC859993 & KC860011 & $\ldots$ & KC860040 & КC860037 \\
\hline & AN035a & KC859963 & $\ldots$ & КС859988 & KC860006 & $\ldots$ & JN715835 & KC860032 \\
\hline & Q043 & KC859964 & $\ldots$ & КС859989 & КС860007 & $\ldots$ & JN715840 & KC860033 \\
\hline & Q030 & КC859965 & $\ldots$ & KC859990 & КC860008 & $\ldots$ & JN715841 & КC860034 \\
\hline & Q003-1 & КС859966 & $\ldots$ & КC859991 & КС860009 & $\ldots$ & JN715842 & KC860035 \\
\hline & R033 & КС859969 & $\ldots$ & КC859994 & КС860012 & $\ldots$ & КС860042 & KC860038 \\
\hline & Q026 & КС859970 & $\ldots$ & KC859995 & KC860013 & $\ldots$ & JN715839 & KC860039 \\
\hline
\end{tabular}

${ }^{\mathrm{z}}$ Abbreviations: actin (ACT; partial), calmodulin (CAL), chitin synthase 1 (CHS-1), glyceraldehyde-3-phosphate dehydrogenase (GAPDH), glutamine synthetase (GS), internal transcribed spacer (ITS), and $\beta$-tubulin 2 (TUB 2). 
room temperature. The precipitate was collected by centrifuging at 13,000 rpm for $15 \mathrm{~min}$. The pellet was washed with $70 \%$ ethanol, air dried, and dissolved in $20 \mu \mathrm{l}$ of sterilized distilled water.

The DNA sequences were obtained in both directions on an Applied Biosystems 3730xl DNA Analyzer (Applied Biosystems Inc.). All sequencing reactions were performed at the Biotechnology Unit of Iowa State University, Ames.

Phylogenetic analysis. The nucleotide sequences were assembled into contigs, edited with ChromasPro version 1.5 (Technelysium Pty. Ltd.), and aligned, using ClustalW as implemented in MEGA version 5.1 (44). Individual gene alignments were concatenated, using FASconCAT version 1.0 (20).

Bayesian Metropolis-coupled Markov chain Monte Carlo (MCMC) analysis was performed on the dataset using MrBayes version 3.2.1 (34), with substitution models determined separately for each partition, according to the corrected Akaike information criterion (AICc) as determined by jModelTest version 0.1.1 (32). For the Bayesian inference analysis, two MCMC chains were run twice for 10,000,000 generations, with trees sampled every 1,000 generations. After omitting the first $25 \%$ of saved trees (burn-in), the remaining sampled trees were used to estimate a $50 \%$ majority rule consensus tree.

Sequences derived in this study have been lodged at GenBank (Table 2) and sequence alignments in TreeBASE (http://treebase. org/treebase-web/home.html) under the accession number S14027. Sequences corresponding to the target genes of ex-type and authentic Colletotrichum isolates described by Damm et al. $(14,15)$ and Weir et al. (47) were obtained from the GenBank and included in the phylogenetic analysis.

\section{Results}

Strain isolation. In the eight production areas where samples were gathered (Fig. 1), anthracnose was detected in the Castilla and Thornless ecotypes. In the Castilla ecotype, anthracnose was observed attacking mostly stems and causing black lesions and dieback whereas, in the Thornless ecotype, the disease mostly attacked floral buds and fruit, causing necrosis and mummification. In total, 240 single-spore isolates of Colletotrichum were included in this study.

Morphological characterization of Colletotrichum isolates. Most of the Colletotrichum isolates produced colonies with uniform or irregular edges, composed of mycelium that were light to dark gray to olive gray on both the upper and lower surfaces (Fig. 3 ), with cottony texture, high density, and low presence of sectors. In cases in which the sporulation occurred normally without injury, spore masses appeared on the colony surface, usually toward the middle of the colony. Spore masses were reddish yellow to salmon pink. In $63 \%$ of isolates, the conidia were oblong-elliptical; other shapes observed were elliptical-fusiform and elliptical (Fig. 3). In $86 \%$ of isolates, appressoria were oval.

On APDA medium, in colonies more than 20 days old, perithecia appeared as hard, dark-brown, or black structures, resistant to rupture. These were either distributed irregularly within the colony or formed aggregates in bands or rows where they met. Microscopy corroborated the presence of unitunicate perithecial asci with thin walls and eight ascospores per ascus. The ascospores were unicellular, hyaline, ellipsoidal, and slightly curved. The sexual state (Glomerella spp.) was observed in 116 isolates from the $C$. gloeosporioides complex and 5 from the C. acutatum complex.

Multiple correspondence analyses of qualitative variables indicated phenotypic variability among isolates, grouping them into eight morphological groups. The highest morphological variability was found in the $C$. acutatum complex composed of eight morphological groups, while the least variability was found in the $C$. gloeosporioides complex with four groups and the $C$. boninense complex with only one group (Table 1).

Morphological group A was formed by 167 isolates (68\%), mostly from the C. gloeosporioides complex (153 isolates), with only 12 isolates from the $C$. acutatum complex. Morphological group B included 41 isolates (17\%), mostly from the C. acutatum complex, with 3 isolates from the $C$. boninense complex. Morphological groups A and B were found in all Andean blackberry-producing areas (Table 1).

Conidium length (2.6 to $15.8 \mu \mathrm{m})$, conidium width (0.7 to 4.6 $\mu \mathrm{m})$, and appressorium length (2.1 to $8.2 \mu \mathrm{m})$ were significantly different $(P<0.001)$ both among isolates and species complexes (Table 1).

Significant differences $(P<0.001)$ in growth rate were observed between isolates. Three groups were identified: (i) isolates with high growth rates (5.0 to $7.1 \mathrm{~mm} \mathrm{day}^{-1}$ ), (ii) isolates with intermediate growth rates ( 3.9 to $5.9 \mathrm{~mm} \mathrm{day}^{-1}$ ), and (iii) isolates with low growth rates $\left(2.3\right.$ to $\left.5.0 \mathrm{~mm} \mathrm{day}^{-1}\right)$. Isolates belonging to the C. gloeosporioides complex had intermediate to high growth rates, those of the $C$. acutatum complex had intermediate rates, and those of the $C$. boninense complex had low rates (Table 1).

Benomyl sensitivity. The evaluated isolates showed a variable response to benomyl. Sensitivity to benomyl significantly differed $(P<0.001)$ between complexes and among complexes or genetic clusters (Table 1). Isolates of the $C$. gloeosporioides complex were sensitive; colony-growth was strongly inhibited (mean of $78.4 \%$ ), with only six isolates inhibited by less than $51 \%$. In contrast, isolates of the $C$. acutatum complex were highly resistant to benomyl. The mean colony-growth inhibition of $C$. acutatum isolates was only $31 \%$, and only 3 of 72 isolates were inhibited by more than $69 \%$. The three isolates of the $C$. boninense complex were intermediately sensitive to benomyl; mean colony-growth inhibition was $66.8 \%$ (Table 1).

Pathogenicity evaluation. Inoculated stems developed reddishbrown lesions that turned violet black over time. The lesions spread around the inoculation point and joined to form one larger, oval lesion. The fungus sporulated abundantly as the lesions matured between 15 and 25 days after inoculation, especially in the area wrapped with Parafilm. Sometimes, perithecia of the teleomorph Glomerella spp. were observed beneath the Parafilm. Control stems developed a small brown area that remained restricted to the inoculation point.

Significant differences $(P<0.001)$ in AUDPC were found both between species complexes, and among isolates within each complex or genetic cluster (Table 1). Isolates of the C. gloeosporioides complex (clusters I and II) were the most aggressive, with mean AUDPC scores of 151.8 and 167.0, respectively. Isolates of the $C$. acutatum complex (clusters IV and V) and two isolates of the $C$. gloeosporioides complex (cluster III) were moderately aggressive, with AUDPC means of 26.9 and 78.5, respectively. The least aggressive isolates belonged to the $C$. boninense complex (cluster VI) and $C$. gloeosporioides complex (cluster VI), with mean AUDPC scores of 1.8 and 3.0, respectively (Table 1).

Molecular characterization. Identifying complexes with specific primers. Primers CaInt2 (specific) and ITS4 amplified a 450bp DNA fragment for $32 \%$ of evaluated isolates and the reference isolates of $C$. acutatum sensu lato (Tom 10 and Tom 21). Primers $C g$ Int (specific) and ITS4 amplified a 450-bp DNA fragment for $67 \%$ of isolates and the reference strains of C. gloeosporioides sensu lato (GND-1 and C339). For primers Coll (specific) and ITS4, an amplification product of 520 bp was obtained for isolates R001 and R033 from Risaralda, CD015-1 from Caldas, and for the reference strains of $C$. boninense sensu lato (Pass 063 and Pass 52). The species identified for the $C$. gloeosporioides and $C$. acutatum complexes were confirmed using primers TBCG and TBCA combined with TB5, which amplified a fragment of about $330 \mathrm{bp}$ for both complexes.

These results indicate that isolates of the $C$. gloeosporioides complex are the primary causal agents of anthracnose in Andean blackberry in Colombia, followed by isolates of the C. acutatum complex and, to a lesser degree, isolates of the $C$. boninense complex (Table 1). A high proportion of isolates assigned to the C. gloeosporioides complex were collected in the Andean blackberry ecotype Castilla. In contrast, a greater proportion of C. acutatum complex isolates were collected in the Thornless ecotype (Fig. 4). 


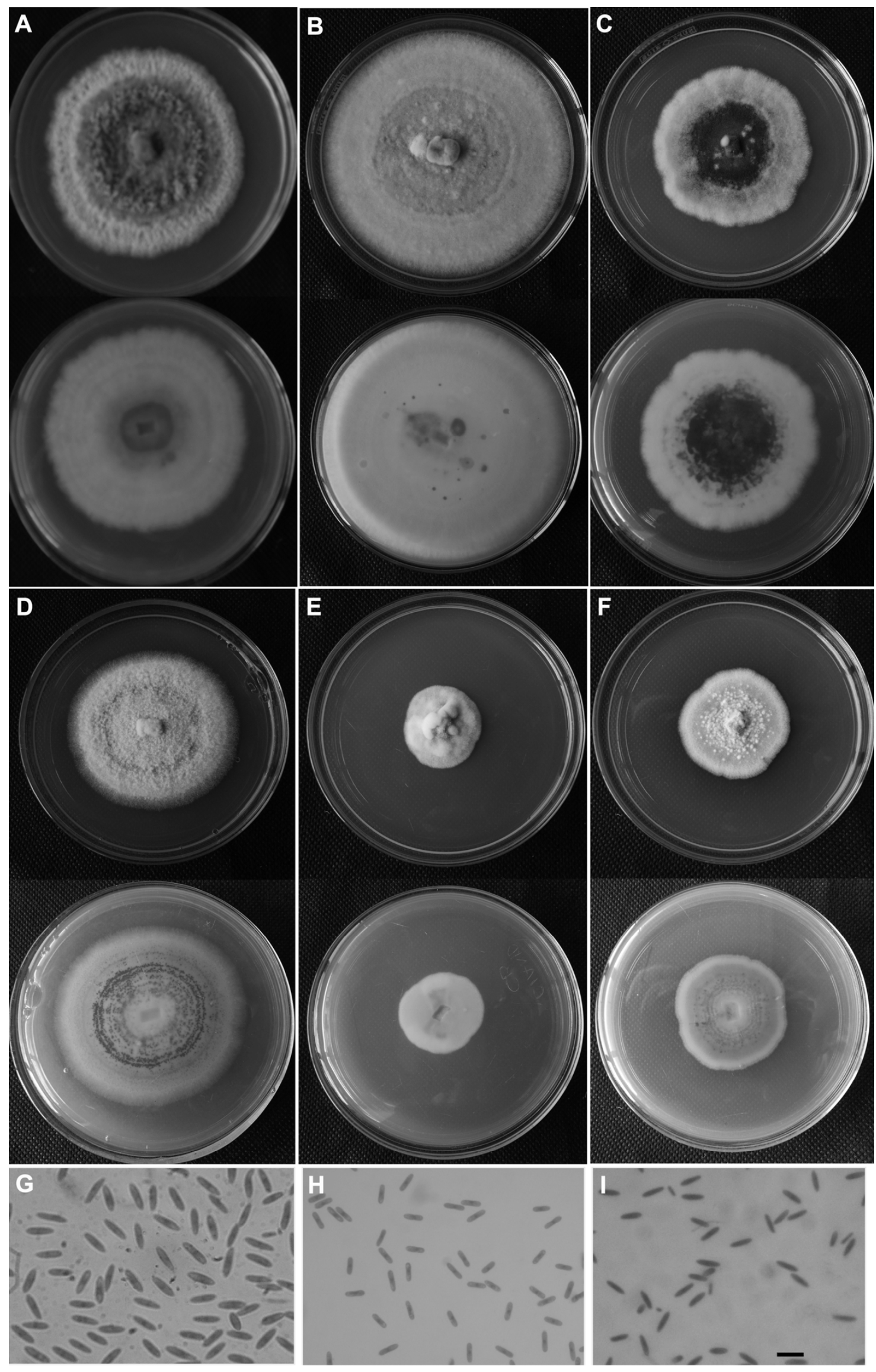

Fig. 3. A-F, Fourteen-day-old colonies of Colletotrichum spp. from Andean blackberry and grown on potato dextrose agar culture medium. Above and reverse views are shown: A, Colletotrichum fructicola (isolate CD009h); B, C. kahawae subsp. ciggaro (isolate R019); C, C. godetiae (isolate AN014); D, C. karstii (isolate R001); E, C. brassicicola (isolate CD015-1); and F, Colletotrichum sp. (isolate R033). G-I, Shapes of Colletotrichum conidia: G, elliptical; H, oblong-elliptical; and I, elliptical-fusiform. Scale bar $=10 \mu \mathrm{m}$. 
Determining the genetic variability of isolates using ISSR primers and the M13 primer. The 240 isolates of Colletotrichum spp. from Andean blackberry were evaluated using five ISSR primers and the MR primer. On average, 192 polymorphic bands each and 14.7 bands per isolate were amplified. Multiple correspondence analysis identified six genetic clusters (Fig. 5), with cluster I comprising $56 \%$ of isolates; cluster II, $9 \%$; cluster III, $2 \%$; cluster IV, $14 \%$; cluster V, $15 \%$; and cluster VI, $4 \%$. The clusters corresponded largely to the Colletotrichum complexes identified through specific primers discussed above. Clusters I and II brought together most (96\%) of the isolates belonging to the C. gloeosporioides complex, including reference strains. The remaining $4 \%$ formed part of clusters III and VI (Fig. 5; Table 1).

Clusters IV (49\%) and V (51\%) comprised all of the isolates belonging to the $C$. acutatum complex, including the reference strains. Isolates in the $C$. boninense complex fell into cluster VI, together with some isolates belonging to other complexes.

Phylogenetic analysis. Most of the 22 new Colletotrichum isolates fell into three well-defined complexes: C. acutatum sensu lato (isolates AN014, AN035a, Q003-1, Q030, Q043, S025-2, and VC017-1), C. gloeosporioides sensu lato (isolates C022-1, CD009h, CD024t, H043, Q025, Q041, R002b, R019, R046, S0073 , and VC097), and C. boninense sensu lato (isolates CD015-1, R001, and R033). That is, the complex-specific primers confirmed the identification of these isolates in their respective complexes.

A dendrogram constructed from a multilocus phylogenetic analysis of isolates belonging to the $C$. gloeosporioides complex is presented (Fig. 6). Isolates CD009h and R002b and the reference strains clustered in a well-defined clade for $C$. fructicola at a Bayesian posterior probability of 1 . The other isolates of the $C$. gloeosporioides complex clustered within the clade for $C$. kahawae at a Bayesian posterior probability of 1 . An analysis of the GS gene sequences indicated that these isolates belong to $C$. kahawae subsp. ciggaro, as determined by a sequence difference and the absence of a 22-bp deletion (48).

With respect to the isolates belonging to the $C$. acutatum complex, Bayesian inference indicated that isolates AN014, S025-2 and VC017-1 from blackberry clustered in a well-defined subclade within clade 5 of $C$. acutatum sensu lato, together with the reference strains for $C$. godetiae. The other isolates belonging to this complex clustered within clade 1 of $C$. acutatum sensu lato However, they did not cluster within subclades defined for previously epitypified reference species and, therefore, were considered as undetermined species within this complex (Fig. 7).

Finally, isolates belonging to the $C$. boninense complex were identified at the species level such as $C$. karstii (isolate R001) and C. brassicicola (isolate CD015-1). However, isolate R033 was not associated with any species in the complex, and was also considered to be an undetermined species (Fig. 8).

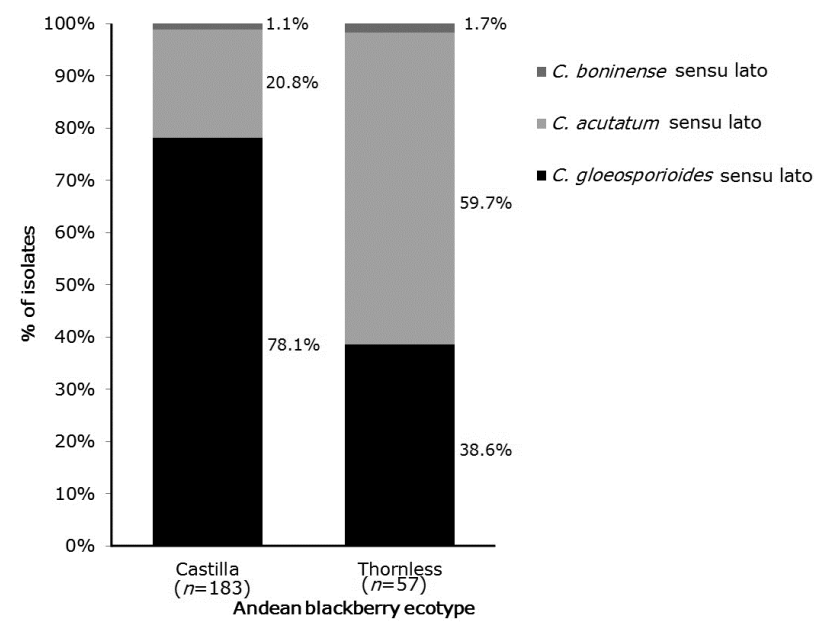

Fig. 4. Colletotrichum species complexes distribution of the isolates obtained from two Andean blackberry ecotypes in Colombia.
We emphasize that the results of the ISSR and M13 test to evaluate the genetic diversity of the isolates within each species complex showed that the genetic groups are associated with specific species of each Colletotrichum complex. That is, for species in the $C$. gloeosporioides complex, cluster I and cluster III comprised isolates identified as C. kahawae subsp. ciggaro while cluster II included all the $C$. fructicola isolates. For species in the $C$. acutatum complex, cluster IV was formed by the $C$. godetiae isolates, and those of cluster V corresponded to undetermined Colletotrichum sp. isolates in clade 1. Cluster VI comprised all the species of the C. boninense complex.

In addition, isolate Q026 did not group with any of the Colletotrichum complexes. Analyses of the ITS region showed this isolate to be intermediate between the $C$. gloeosporioides and $C$. boninense complexes (data not shown). This isolate was located at cluster VI, in the MCA analysis (Fig. 5), together with the Colletotrichum isolates belonging to the $C$. boninense complex.

\section{Discussion}

The PCR amplification of the ribosomal DNA-ITS region and the $\beta$-tubulin gene with specific DNA primers has been used in earlier molecular studies to determine the etiology of anthracnose in many crops, especially fruit crops $(5,7,21,28,31,35)$. However, these primers cannot be considered species specific, because of the similarity in sequences of the ITS region and $\beta$-tubulin gene of different Colletotrichum spp. This has caused misidentification of many strains that were previously identified as either $C$. gloeosporioides or $C$. acutatum at the species level. Nevertheless, as demonstrated by our study and Alvarez et al. (2), these primers can be considered to be particularly important for identifying isolates at the complex level.

Isolates of the $C$. gloeosporioides complex were present in all production areas evaluated, predominating in those regions where the Castilla ecotype was planted (Antioquia, Cundinamarca, Huila, Santander, and Valle del Cauca). In contrast, isolates of the $C$. acutatum complex were found more frequently in the coffee-growing regions (Caldas, Quindío, and Risaralda), where the thornless blackberry ecotype was predominant.

Although minimally present, isolates of the $C$. boninense complex in blackberry-producing areas of Colombia may indicate its high plasticity to adapt to different hosts; it has already been detected in other fruit species such as mango, tree tomato, and passion fruit species (1).

In this study, the use of ISSR and the M13 primers divided Colletotrichum populations collected from Colombian Andean blackberry into molecular clusters exclusive to each complex and

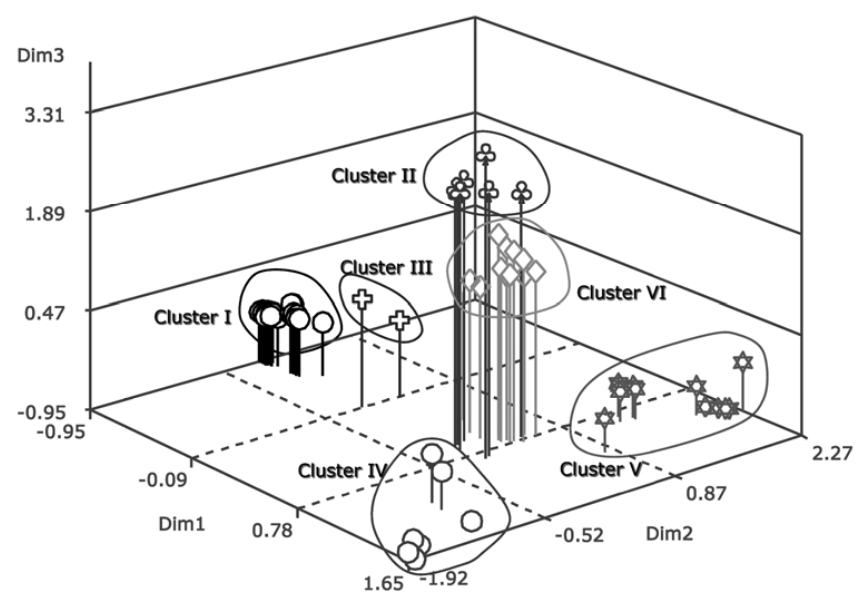

Fig. 5. Three-dimensional scatter plot resulting from a multiple correspondence analysis (MCA) shows the relationships among 240 Colletotrichum isolates obtained from Andean blackberry and the three Colletotrichum species complexes: Colletotrichum gloeosporioides complex (clusters I, II, and III), C. acutatum complex (clusters IV and V), and C. boninense complex (cluster VI). The plot was derived from an analysis of intersimple sequence repeat and M13 primers. 
into other clusters shared among complexes. Regardless of the marker used, the two most important complexes (C. gloeosporioides and $C$. acutatum) appear as one or two predominant genetic clusters in each of the blackberry-producing regions of Colombia. Such distribution may be attributed to the existence of clonal lineages, which have been disseminated throughout Colombia as a result of vegetative propagation by farmers. Similarly, the blackberry ecotypes used to establish new crops may have favored the presence of a given fungal species or complex in some production areas and in certain plant tissues.

Differences observed in the isolates' aggressiveness on stems of the blackberry ecotype Castilla could be attributed to the infectivity of the three complexes on different plant tissues, as indicated by

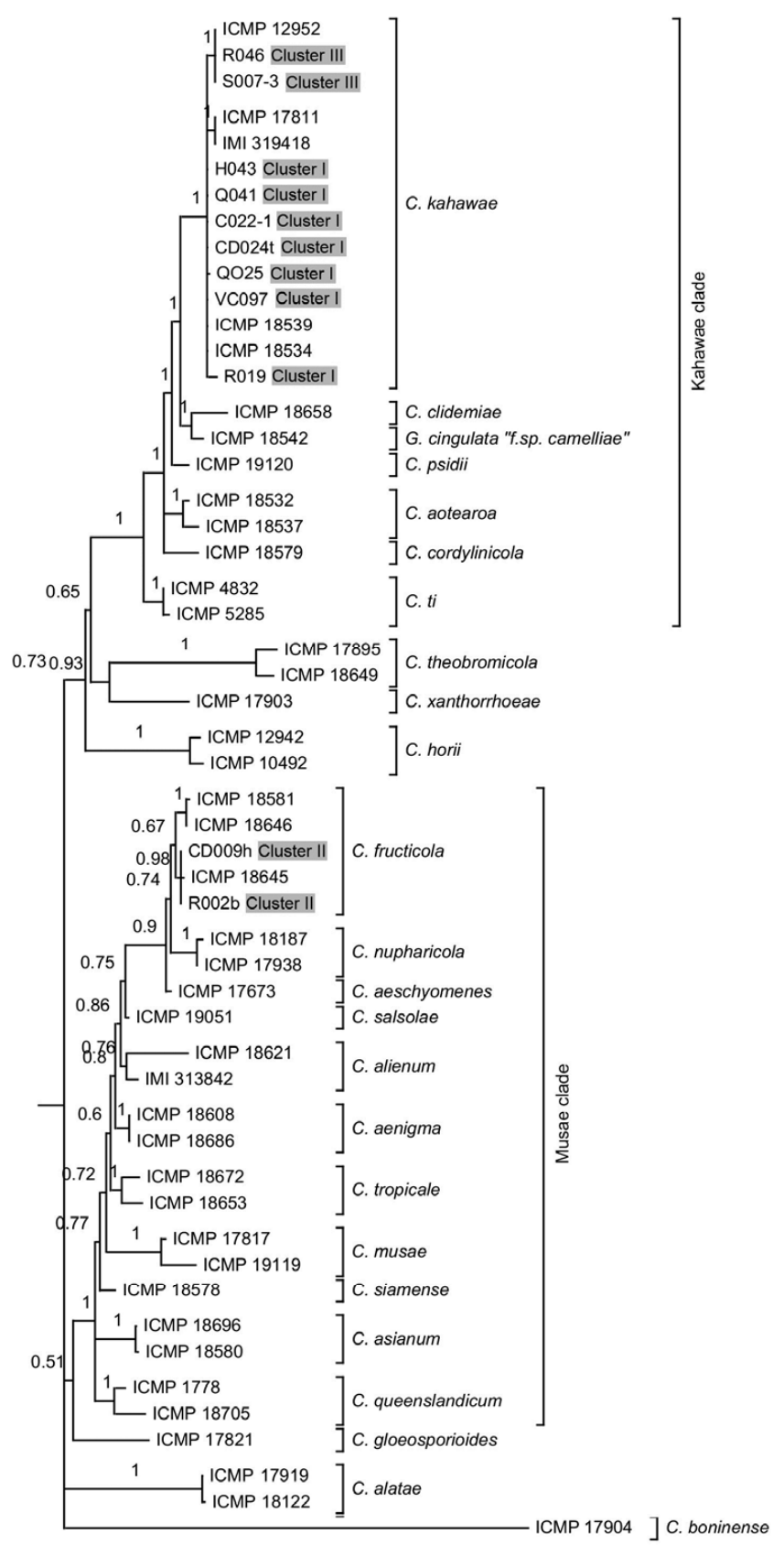

$$
\text { سسبسلسسبسا } 0.0
$$

Fig. 6. Phylogenetic consensus tree based on Bayesian inference, illustrating the relationships within the Colletotrichum gloeosporioides complex of isolates obtained from Andean blackberry. The tree was built using concatenated sequences of the genes ACT, CHS-1, CAL, GAPDH, ITS, and TUB 2, and run for $1 \times 10^{7}$ generations, each with a separate model of DNA evolution. C. boninense sensu stricto (ICMP 17904) was used as the outgroup. symptom type and tissue sampling conducted to obtain the isolates. More specifically, $C$. gloeosporioides sensu lato and $C$. boninense sensu lato were closely associated with stems, black lesions, and dieback symptoms. C. acutatum sensu lato isolates from fruit and floral buds produced mummification and necrosis. The simultaneous appearance of isolates from the three complexes was sometimes observed on the same tissues, especially stems, possibly indicating cross-infection under field conditions.

The apparent differences in infection strategies of the three complexes may be attributed to differences in pathogenicity, as found in tests carried out under controlled greenhouse conditions. Peres et al. (28) demonstrated that $C$. acutatum sensu lato has different life forms resulting from colonization strategies according to host,

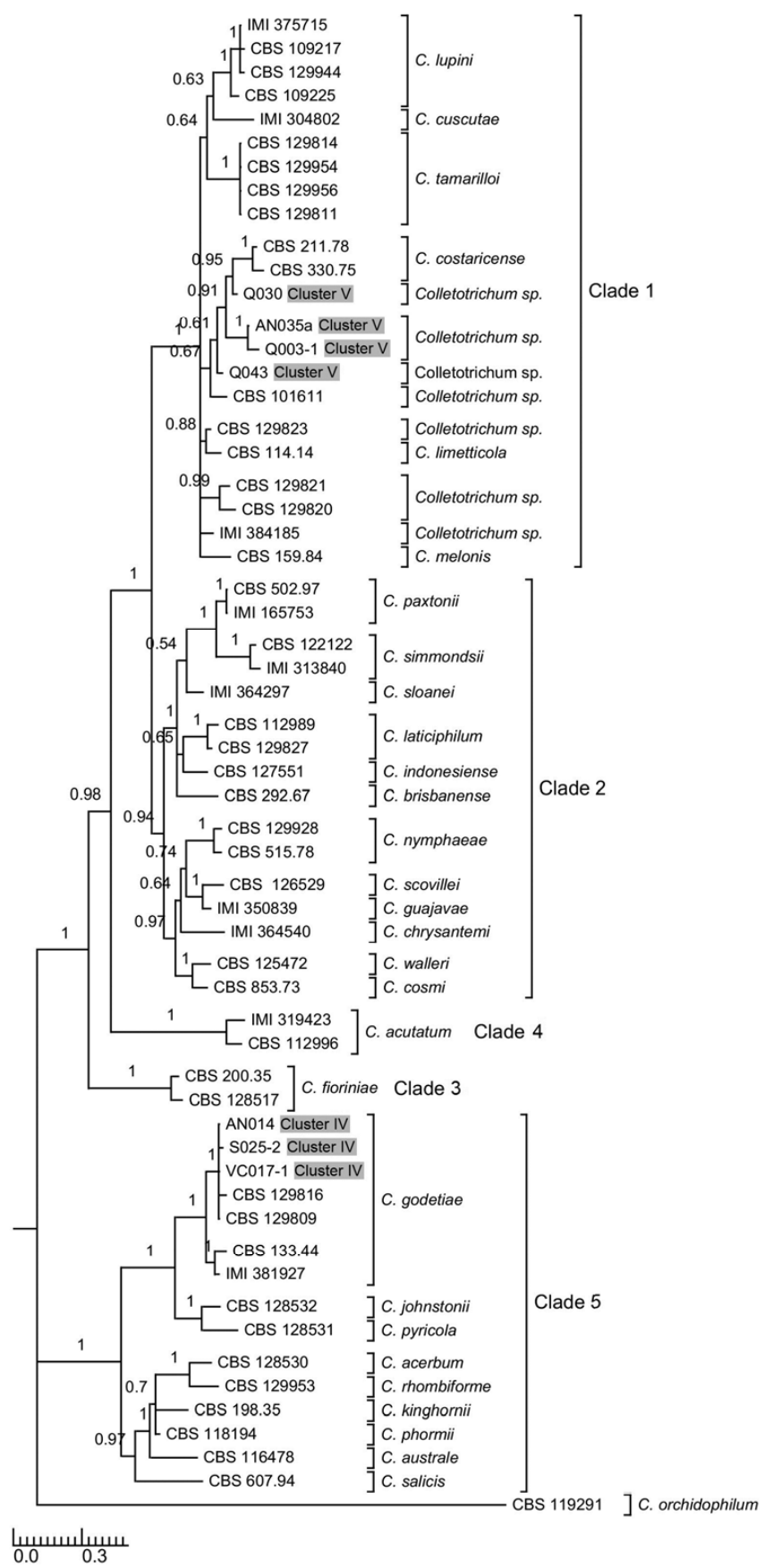

Fig. 7. Phylogenetic consensus tree based on Bayesian inference, illustrating the relationships within the Colletotrichum acutatum species complex of Colletotrichum isolates obtained from Andean blackberry. The tree was built using concatenated sequences of the genes ACT, CHS-1, GAPDH, ITS, and TUB 2, and run for $1 \times 10^{7}$ generations, each with a separate model of DNA evolution. C. orchidophillum (CBS 119291) was used as the outgroup. 
ability to move between hosts, and changing genetic relationships between isolates from different hosts. C. acutatum sensu lato is a highly specialized pathogen in the way it attacks host tissues, particularly in apple and orange, where leaves may be disease-free but the flowers and fruit are severely infected (28).

Likewise, in blackberry, the C. acutatum sensu lato pathogen may preferentially attack flowers and fruit, with stems remaining relatively immune. This phenomenon would explain the results obtained for artificial inoculations of detached stems. However, the pathogenicity of this species complex in blackberry and its preference for specific tissues such as fruit and floral buds cannot be conclusively demonstrated because of the difficulties of inoculating clusters of completely disease-free floral buds. Therefore, a more precise methodology must be developed to study differences in pathogenicity between the various complexes under controlled laboratory or greenhouse conditions.
The status of the $C$. acutatum complex, which is currently identified as having a low level of pathogenicity and low incidence, could change to being more aggressive with the increasing presence of a more susceptible blackberry genotype.

In this study, the multilocus phylogenetic analysis resolved $C$. godetiae (clade 5, molecular group A5) and some indeterminate species (clade 1, group A8) in the $C$. acutatum complex; $C$. kahawae subsp. ciggaro and C. fructicola in the C. gloeosporioides complex; and C. karstii, C. brassicicola, and one indeterminate species in the $C$. boninense complex. To our knowledge, this is the first report of these species attacking Andean blackberry.

All of the identified taxa have been isolated from other hosts of economic importance, indicating the capacity of these species to cross-infect various host plants (30). For example, in Colombia, C. karstii was reported as attacking Annona muricata, Passiflora edulis, Musa AAA, and Solanum betaceum $(2,15)$. C. gode-

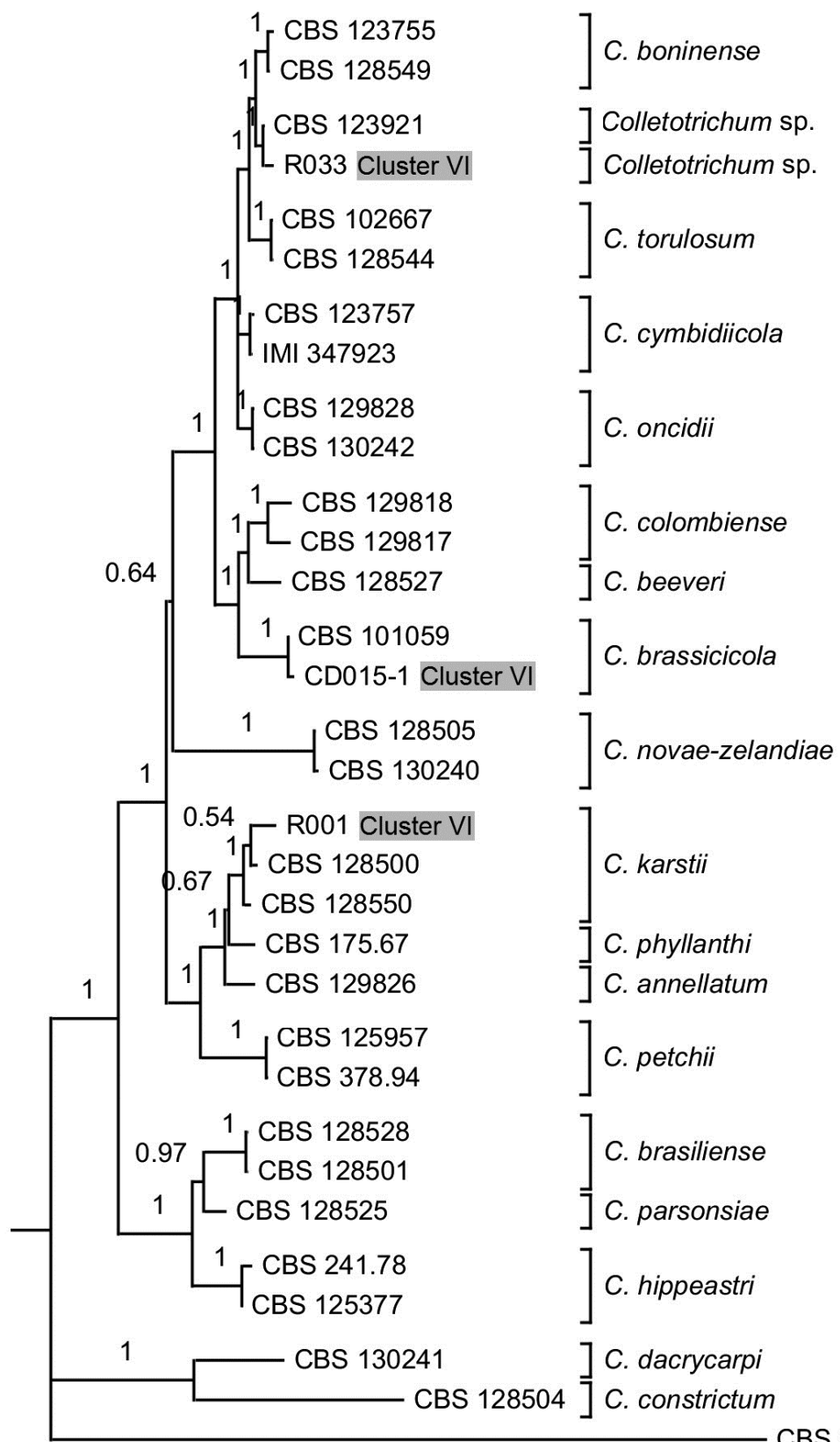

CBS 112999 ] C. gloeosporioides

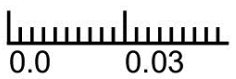

Fig. 8. Phylogenetic consensus tree based on Bayesian inference, illustrating the relationships within the Colletotrichum boninense complex of isolates obtained from Andean blackberry. The tree was built using concatenated sequences of the genes ACT, CHS-1, GAPDH, ITS, and TUB 2, and run for $1 \times 10^{7}$ generations, each with a separate model of DNA evolution. C. gloeosporioides sensu stricto (CBS 112999) was used as the outgroup. 
tiae was also reported as causing anthracnose in $S$. betaceum, and Latin American isolates may occupy a separate subclade from other strains collected outside this region (14). This finding was confirmed by our study, with strains from Andean blackberry being closely related genetically to strains CBS 129816 and CBS 129809 , isolated from $S$. betaceum in Colombia. Thus, we suggest that these strains must be reevaluated, possibly considering them a subspecies of $C$. godetiae or a new species specific to the neotropics and subtropics of the western hemisphere.

Likewise, the isolates belonging to an undetermined species within the $C$. acutatum complex clustered with species that were representative of clade 1 of $C$. acutatum sensu lato, the origin of which is restricted to Central and South America or the southern United States (14). Particularly in this clade, it would be necessary to test other markers that would permit us to delimit the unnamed species in some species already recognized or describe them as new taxa.

Only $C$. fioriniae and $C$. godetiae had previously been associated with Rubus spp. (14). Our study corroborated the association of $C$. godetiae and identified four other species, both pathogenic to blackberry and highly dispersed geographically.

Using a gene sequence from this study (GS), we found isolates from blackberry that belonged to C. kahawae subsp. ciggaro, and confirmed that they did not belong to $C$. kahawae subsp. kahawae (coffee-berry pathogen), a species that is of high quarantine importance in Colombia and which is found to a limited extent in Africa $(45,46,47)$.

Despite the low incidence in Andean blackberry in Colombia, the $C$. boninense complex was represented by $C$. brassicicola, $C$. karstii, and an undetermined species.

Our findings represent an important contribution to the etiology and epidemiology of anthracnose of Andean blackberry in Colombia. It establishes the existence of a diversity of Colletotrichum spp. associated with the disease in this crop and, most probably, in other fruit species. Our study facilitates the development of future epidemiological research in Andean blackberry and other fruit crops, offering relevant information to the design of management strategies such as chemical management, crop rotation, and the evaluation of resistance in Rubus germplasm to the different Colletotrichum spp. reported here.

\section{Acknowledgments}

This work was financially supported by the Regional Fund for Agricultural Technology (FONTAGRO), ID 16 (2007 to 2010). We thank P. Zapata and C. Escobar for field surveys assistance, M. M. Marroquín and J. B. Cuasquer for data analysis, M. W. Blair for reviewing the manuscript, and the reviewers for their useful comments.

\section{Literature Cited}

1. Afanador-Kafuri, L., Minz, D., Maymon, M., and Freeman, S. 2003. Characterization of Colletotrichum isolates from tamarillo, passiflora, and mango in Colombia and identification of a unique species from the genus. Phytopathology 93:579-587.

2. Alvarez, E., Gañán, L., Rojas, A., Mejía, J. F., Llano, G. A., and González, A. 2014. Diversity and Pathogenicity of Colletotrichum species isolated from Soursop in Colombia. Eur. J. Plant Pathol. 139:325-338. Online publication. doi:10.1007/s10658-014-0388-7

3. Alvarez, E., Ospina, C. A., Mejía, J. F., and Llano, G. A. 2004. Caracterización morfológica, patogénica y genética del agente causal de la antracnosis (Colletotrichum gloeosporioides) en guanábana (Annona muricata). Fitopatol. Colomb. 28:1-8.

4. Álvarez, R., Barrero, L. S., Beltrán, C. R., and Cotes A. M. 2009. Capacitación sobre el manejo de un lote experimental para el cultivo de la Mora en Silvania (Cundinamarca). Page 9-24 in: Caracterización, evaluación y producción de material limpio de mora con alto valor agregado. L. S. Barrero, ed. Produmedios, Bogotá, Colombia.

5. Arenas, A., Alvarez, E., Afanador-Kafuri, L., Mejía J. F., and González, A. 2007. Especies de Colletotrichum asociadas con la antracnosis de la mora de Castilla (Rubus glaucus Benth.) en el Valle del Cauca. Fitopatol. Colomb. 31:7-14

6. Botero, M. J., and Franco, G. 2007. Identificación y caracterización preliminar del agente causal de la mancha necrótica de las hojas de la mora (Rubus glaucus) en el muncipio de Trujillo (Valle del Cauca, Colombia). Rev. Corpoica Cienc. Tecnol. Agropec. 8:22-25.

7. Brown, A. E., Sreenivasaprasad, S., and Timmer, L. 1996. Molecular char- acterization of slow-growing orange and key lime anthracnose strains of Colletotrichum from citrus as C. acutatum. Phytopathology 86:523-527.

8. Cai, L., Hyde, K. D., Taylor, P. W. J., Weir, B. S., Waller, J., Abang, M. M., Zhang, J. Z., Yang, Y. L., Phoulivong, S., Liu, Z. Y., Prihastuti, H., Shivas, R. G., McKenzie, E. H. C., and Johnston, P. R. 2009. A polyphasic approach for studying Colletotrichum. Fungal Divers. 39:183-204.

9. Cannon, P. F., U. Damm, Johnston, P. R., and Weir. B. S. 2012. Colletotrichum - current status and future directions. Stud. Mycol. 73:181-213.

10. Carbone, I., and Kohn, L. M. 1999. A method for designing primer sets for speciation studies in filamentous ascomycetes. Mycologia 91:553-556.

11. Chaky, J., Anderson, K., Moss, M., and Vaillancourt, L. 2001. Surface hydrophobicity and surface rigidity induce spore germination in Colletotrichum graminicola. Phytopathology 91:558-564.

12. Crouch, J. A., Bein, L. A., Cortese, L. M., Bonos, S. A., and Clark, B. B. 2009a. Anthracnose disease of switchgrass caused by the novel fungal species Colletotrichum navitas. Mycol. Res. 113:1411-1421.

13. Crouch, J. A., Clarke, B. B., White, J. F., and Hillman, B. I. 2009c. Systematic analysis of the falcate-spored graminicolous Colletotrichum and a description of six new species of the fungus from warm-season grasses. Mycologia 101:717-732

14. Damm, U., Cannon, P. F., Woudenberg, J. H. C., and Crous, P. W. 2012. The Colletotrichum acutatum species complex. Stud. Mycol.73:37-113.

15. Damm, U., Cannon, P. F., Woudenberg, J. H. C., Johnston, P. R., Weir, B. S., Tan, Y. P., Shivas, R. G., and Crous, P. W. 2012. The Colletotrichum boninense species complex. Stud. Mycol. 73:1-36.

16. Franco, G., and Giraldo, M. 2002. El cultivo de la mora: Manual de asistencia técnica, 5th ed. Corporación Colombiana de Investigación Agropecuaria (CORPOICA), Federación Nacional de Cafeteros de Colombia, Servicio Nacional de Aprendizaje (SENA Comité Técnico Agropecuario de Risaralda, and Unidad Municipal de Asistencia Técnica Agropecuaria (UMATA), Risaralda, Colombia.

17. Glass, N. L., and Donaldson, G. C. 1995. Development of primer sets designed for use with the PCR to amplify conserved genes from filamentous ascomycetes. Applied and Environmental Microbiology 61:1323-1330.

18. Guerber, J. C., Liu, B., Correll, J. C., and Johnston, P. R. 2003. Characterization of diversity in Colletotrichum acutatum sensu lato by sequence analysis of two gene introns, mtDNA and intron RFLPs, and mating compatibility. Mycologia 95:872-895.

19. Jiménez, D., Cock, J., Satizábal, F., Barreto, M., Pérez-Uribe, A., Jarvis, A., and Van Damme, P. 2009. Analysis of Andean blackberry (Rubus glaucus) production models obtained by means of artificial neural networks exploiting information collected by small-scale growers in Colombia and publicly available meteorological data. Comput. Electron. Agric. 69:198-208.

20. Kück, P., and Meusemann, K. 2010. FASconCAT: Convenient handling of data matrices. Mol. Phylogenet. Evol. 56:1115-1118.

21. Lima, J. S., Figueiredo, J. G., Gomes, R. G., Stringari, D., Goulin, E. H., Adamoski, D., Kava-Cordeiro, V., Galli-Terasawa, L. V., and Glienke, C. 2012. Genetic diversity of Colletotrichum spp., an endophytic fungi in a medicinal plant, Brazilian pepper tree. ISRN Microbiol. Online journal. Vol. 2012, Art. ID 215716. doi:10.5402/2012/215716

22. Mahuku, G. S. 2004. A simple extraction method suitable for PCR-based analysis of plant, fungal and bacterial DNA. Plant Mol. Biol. Rep. 22:7181 .

23. Meret, M., Brat, P., Mertz, M., Lebrun, M., and Gaeta, Z. 2011. Contribution to aroma potential of Andean blackberry (Rubus glaucus Benth.). Food Res. Int. 44:54-60.

24. Mills, P. R., Sreenivasaprasad, S., and Brown, A. E. 1992. Detection and differentiation of Colletotrichum gloeosporioides isolates using PCR. FEMS Microbiol. Lett. 98:137-144.

25. Munsell Color. 1990. Munsell Soil Color Charts, revised edition. Macbeth Division of Kollmorgen Instruments Corporation, Baltimore, MD.

26. O'Donnell, K., Nirenberg, H., Aoki, T., and Cigelnik, E. 2000. A multigene phylogeny of the Gibberella fujikuroi species complex: Detection of additional phylogenetically distinct species. Mycoscience 41:61-78.

27. Osorio, C., Hurtado, N., Dawid, C., Hofmann, T., Heredia-Mira, F. J., and Morales, A. L. 2012. Chemical characterisation of anthocyanins in tamarillo (Solanum betaceum Cav.) and Andes berry (Rubus glaucus Benth.) fruits Food Chem. 132:1915-1921.

28. Peres, N. A., Timmer, L. W., Adaskaveg, J. E., and Corell, J. C. 2005. Lifestyles of Colletotrichum acutatum. Plant Dis. 41:84-95.

29. Phoulivong, S., Cai, L., Chen, H., McKenzie, E. H. C., Abdelsalam, K., Chukeatirote, E., and Hyde, K. D. 2010. Colletotrichum gloeosporioides is not a common pathogen on tropical fruits. Fungal Divers. 44:33-43.

30. Phoulivong, S., McKenzie, E. H. C., and Hyde, K. D. 2012. Cross infection of Colletotrichum species; a case study with tropical fruits. Curr. Res. Environ. Appl. Mycol. 2:99-111.

31. Pileggi, S. A., Vieira de Oliveira, S. F., Andrade, C. W., Vicente, V. A., Dalzoto, P. do R., da Cruz, G., Gabardo, J., Massola, N., Tozze, H. J., Pillegi, M., Kava-Corderiro, V., Galli-Terasawa, L. V., Pimentel, I. C., Stringari, D., and Glienke, C. 2009. Molecular and morphological markers for rapid distinction between two Colletotrichum species. Can. J. Microbiol. 55:1076-1088.

32. Posada, D. 2008. jModelTest: Phylogenetic model averaging. Mol. Biol. Evol. 25:1253-1256. 
33. Prihastuti, H., Cai, L., Chen, H., McKenzie, E. H. C., and Hyde, K. D. 2009. Characterization of Colletotrichum species associated with coffee berries in Chiang Mai, Thailand. Fungal Divers. 39:89-109.

34. Ronquist, F., Teslenko, M., van der Mark, P., Ayres, D., Darling, A., Höhna, S., Larget, B., Liu, L., Suchard, M., and Huelsenbeck, J. P. 2012. MrBayes v. 3.2: Efficient Bayesian phylogenetic inference and model choice across a large model space. Syst. Biol. 61:539-542.

35. Rueda, K., Saldarriaga, A., Cadavid-Restrepo, G. E., Saldamando, C. I., Cañas, G. P., and Arango, R. E. 2013. Differential organ distribution, pathogenicity and benomyl sensitivity of Colletotrichum spp. from blackberry plants in northern Colombia. J. Phytopathol. 161:246-253.

36. Saldarriaga-Cardona, A., Castaño Zapata, J., and Arango Isaza, R. A. 2008. Caracterización del agente causante de la antracnosis en tomate de árbol, manzano y mora. Rev. Acad. Colomb. Cienc. Exactas, Fis. Nat. 32:145-156.

37. SAS Institute Inc. 2008. SAS/STAT 9.2 User's Guide. SAS Institute Inc., Cary, NC.

38. Sreenivasaprasad, S., Sharada, K., Brown, A. E., and Mills P. R. 1996. PCRbased detection of Colletotrichum acutatum on strawberry. Plant Pathol. 45:650-655.

39. Stephenson, S. A., Green, J. R., Manners, J. M., and Maclean, D. J. 1997. Cloning and characterisation of glutamine synthetase from Colletotrichum gloeosporioides and demonstration of elevated expression during pathogenesis on Stylosanthes guianensis. Curr. Genet. 31:447-454.

40. Stewart, P. J., Clark, J. R., and Fenn, P. 2004. Evaluation of resistance to Erwinia amylovora and Botryosphaeria dothidea in eastern US blackberry cultivars. in: Horticultural Studies 2003. J. A. Robbins, B. Murphy, and M.
Richardson, eds. Ark. Agric. Exp. Stn. Res. Ser. 520:32-34.

41. Talhinhas, P., Sreenivasaprasad, S., Neves-Martins, J., and Oliveira, H. 2005. Molecular and phenotypic analyses reveal association of diverse Colletotrichum acutatum groups and low level of C. gloeosporioides with olive anthracnose. Appl. Environ. Microbiol. 71:2987-2998.

42. Tamayo, P. J. 1995. Muerte descendente de ramas y mildeo velloso de la mora en Antioquia. ASCOLFI Inf. 21:72-73.

43. Tamayo, P. J., and Peláez, A. 2000. Caracterización de daños y pérdidas causadas por enfermedades del fruto de la mora de Castilla (Rubus glaucus Benth.) en Antioquia. Pages 174-179 in: Proc. III Seminario de Frutales de Clima Frío Moderado. Manizales, Colombia.

44. Tamura, K., Peterson, D., Peterson, N., Stecher, G., Nei, M., and Kumar, S. 2011. MEGA5: Molecular evolutionary genetics analysis using maximum likelihood, evolutionary distance, and maximum parsimony methods. Mol Biol. Evol. 28:2731-2739.

45. Tao, G., Hyde, K. D., and Cai, L. 2013. Species-specific real-time PCR detection of Colletotrichum kahawae. J. Appl. Microbiol. Online publication. doi:10.1111/jam.12068

46. Waller, J. M., Bridge, P. D., Black, R., and Hakiza, G. 1993. Characterization of the coffee berry disease pathogen, Colletotrichum kahawae sp. nov. Mycol. Res. 97:989-994.

47. Weir, B. S., Johnston, P. R., and Damm, U. 2012. The Colletotrichum gloeosporioides species complex. Stud. Mycol.73:115-180.

48. White, T. J., Bruns, T., Lee, S., and Taylor, J. 1990. Amplification and direct sequencing of fungal ribosomal RNA genes for phylogenetics. Pages 315 322 in: PCR Protocols: A Guide to Methods and Applications. M. A. Innis, D. H. Gelfand, and J. J. Sninsky, eds. Academic Press, San Diego, CA. 